\title{
MicroRNA-338-3p targets SOX4 and inhibits cell proliferation and invasion of renal cell carcinoma
}

\author{
ZHIGANG TONG $^{1}$, XIANFENG MENG $^{1}$, JINSONG WANG $^{1}$ and LIXIN WANG ${ }^{2}$ \\ ${ }^{1}$ Department of Urinary Surgery, The Affiliated Hospital, Changchun University of Chinese Medicine; \\ ${ }^{2}$ Department of Medical Insurance, Jilin Academy of Chinese Medicine Sciences, Changchun, Jilin 130021, P.R. China
}

Received September 21, 2016; Accepted May 11, 2017

DOI: 10.3892/etm.2017.5169

\begin{abstract}
MicroRNA (miR)-338-3p has been reported to be involved in tumor progression and development in various types of cancer. However, the biological function of miR-338-3p and its related molecular pathways involved in the progression of renal cell carcinoma (RCC) are unknown. The present study aimed to investigate the biological role and underlying mechanism of miR-338-3p in RCC cells. It was demonstrated that miR-338-3p expression level was significantly downregulated $(\mathrm{P}<0.05)$ in $\mathrm{RCC}$ tissues and cell lines. Clinical association analysis indicated that low expression of miR-338-3p was significantly associated with advanced TNM stage and lymph node metastasis $(\mathrm{P}<0.05)$. Function assays revealed that restoration of miR-338-3p in RCC cells significantly inhibited cell proliferation, colony formation, migration and invasion $(\mathrm{P}<0.05)$. Notably, sex-determining region Y-box 4 (SOX4) was identified as a direct target of miR-338-3p in RCC cells through a luciferase reporter assay, reverse transcription-quantitative polymerase chain reaction and western blot analysis. Furthermore, SOX4 overexpression partially rescued miR-338-3p-mediated inhibition of cell proliferation, colony formation, migration and invasion in RCC cells. These results suggested that miR-338-3p functioned as a tumor suppressor in RCC cells by modulating SOX4, suggesting that miR-338-3p may have a potential use in the treatment of RCC.
\end{abstract}

\section{Introduction}

Renal cell carcinoma (RCC), accounting for 2-3\% of all tumor malignancies in humans, is the most lethal urologic tumor (1). Despite increased early detection of RCC and more frequent surgery or other therapy, the prognosis remains poor due to metastasis of RCC and its low response to chemotherapy and

Correspondence to: Professor Lixin Wang, Department of Medical Insurance, Jilin Academy of Chinese Medicine Sciences, 1745 Gongnong Road, Changchun, Jilin 130021, P.R. China E-mail: 1596152282@qq.com

Key words: microRNA, microRNA-338-3p, renal cell carcinoma, sex-determining region Y-box 4, proliferation radiotherapy $(2,3)$. Thus, there is an urgent need to elucidate the mechanisms of RCC progression to provide useful information for the clinical management of this disease.

MicroRNA (miR) are a class of short, single stranded, non-coding RNA molecules, of 19-25 nucleotides in length, that act as important regulators of gene expression by binding to the 3'-untranslated region (UTR) of specific target mRNA (4). Study has demonstrated that miR are involved in various biological processes, such as cell growth, migration, invasion, apoptosis, metabolism and cellular differentiation $(5,6)$. Accumulating evidence suggests that miR could have oncogenic or tumor-suppressive roles in the regulation of cell growth, migration and invasion by repressing their target genes $(7,8)$. Recently, some miR have been reported to be involved in RCC procession, and may serve as diagnostic markers or therapy agents for $\operatorname{RCC}(9,10)$.

miR-338-3p, located on the 7th intron of the apoptosis-associated tyrosine kinase gene, has been reported to be downregulated in many types of cancer, such as hepatocellular carcinoma $(11,12)$, colorectal cancer $(13)$, ovarian cancer (14), gastric cancer $(15,16)$ and breast cancer $(17)$. However, little is known about the biological role and underlying mechanism of miR-338-3p in RCC. The present study therefore investigated the biological functions and the mechanism of miR-338-3p in RCC progression. It was demonstrated that miR-338-3p was downregulated in RCC tissues and cell lines, and miR-338-3p expression was associated with clinicopathological characteristics in RCC. It was also observed that miR-338-3p overexpression inhibited cell proliferation, colony formation, migration and invasion of RCC by repressing sex-determining region Y-box 4 (SOX4). Studies such as these may contribute to the understanding of the molecular mechanisms underlying RCC development.

\section{Materials and methods}

Clinical samples. A total of 48 RCC samples and adjacent normal tissues were collected from patients (mean age, 52.5 \pm 4.5 years; age range, 43.2-75.4 years; 21 males and 27 females) who underwent resection of their primary RCC at the Department of General Surgery, The Affiliated Hospital, Changchun University of Chinese Medicine (Changchun, China) between April 2012 and December 2014. All participants provided written informed consent prior to participating 
in the study. The present study was approved by the Medicine Ethics Committee of Changchun University of Chinese Medicine. All tissue samples were immediately stored in liquid nitrogen until use. The clinicopathological information of the patients, including age, sex, tumor size, TNM stage and lymph node metastasis was recorded (Table I). No patients had received chemotherapy or radiotherapy prior to surgery.

Cell lines and transfection. Four RCC cell lines (786-O, ACHN, Caki-1 and Caki-2) and a human renal proximal tubule epithelial cell line (HK-2) were purchased from the Type Culture Collection of the Chinese Academy of Sciences (Shanghai, China). Cells were cultured in Dulbecco's modified Eagle's medium (DMEM; Gibco; Thermo Fisher Scientific, Inc., Waltham, MA, USA) supplemented with $10 \%$ fetal bovine serum (FBS; Invitrogen; Thermo Fisher Scientific, Inc.), $100 \mathrm{IU} / \mathrm{ml}$ penicillin and $100 \mathrm{IU} / \mathrm{ml}$ streptomycin at $37^{\circ} \mathrm{C}$ in a $5 \% \mathrm{CO}_{2}$ humidified incubator.

miR-338-3p mimic (miR-338-3p, GUUGUUUUAGUGAC UACGACCU) and corresponding negative control (NC, GUC CTUGCUCGAGCGAGGUGA) mimic (miR-NC) were purchased from GeneCopoeia, Inc. (Rockville, MD, USA). A SOX4 overexpression plasmid was purchased from OriGene Technologies, Inc., (Beijing, China). miR-338-3p (100 nM), miR-NC (100 nM) or the SOX4 plasmid (100 ng) were transfected into RCC cells using Lipofectamine 2000 (Invitrogen; Thermo Fisher Scientific, Inc.), according to the manufacturer's instructions.

RNA extraction and reverse transcription-quantitative polymerase chain reaction ( $R T-q P C R)$. Total RNA from tissues and cells was extracted using TRIzol (Invitrogen; Thermo Fisher Scientific, Inc.). To detect miR-338-3p expression, the RNA was reverse transcribed into cDNA using a TaqMan miRNA Reverse Transcription kit (Thermo Fisher Scientific, Inc.), and were quantified using a TaqMan Human MicroRNA Assay kit (Thermo Fisher Scientific, Inc.). Both steps were conducted according to the manufacturer's instructions. Primers for miR-338-3p and U6 (GeneCopoeia, Inc.) were used as follows: miR-338-3p, 5'-CCGCTCGAGGCCT GCAGAGCAGGACCTGGG-3' (sense) and 5'-ATAAGAATG CGGCCGCATACAAAAACCTTTTATTGACTGTATTTC TTCTC-3' (antisense); U6, 5'-TGCGGGTGCTCGCTTCGG CAGC-3' and 5'-CCAGTGCAGGGTCCGAGGT-3' (antisense). U6 was used as an internal control. For detection of SOX4, cDNA was synthesized using a PrimerScript RT reagent kit (Takara Biotechnology Co., Ltd., Dalian, China), and was quantified using a SYBR Green PCR Master Mix (Takara Biotechnology Co., Ltd.) on an ABI 7900HT Fast Real-Time PCR system (Thermo Fisher Scientific, Inc.). The primers used for SOX4 and GAPDH were as previously described (18). GAPDH was used as an internal control. The following PCR conditions were used: Denaturation at $94^{\circ} \mathrm{C}$ for $5 \mathrm{~min}$, followed by 40 cycles of amplification (denaturation at $94^{\circ} \mathrm{C}$ for $10 \mathrm{sec}$, annealing at $58^{\circ} \mathrm{C}$ for $30 \mathrm{sec}$ and extension at $72^{\circ} \mathrm{C}$ for $30 \mathrm{sec}$ ). The comparative $2^{-\Delta \Delta \mathrm{Cq}}$ method was used for relative quantification (19).

Cell proliferation and colony formation. The proliferation of RCC cell lines (786-O and Caki-1) was examined by MTT
Table I. Correlation between clinicopathological features and miR-338-3p expression in RCC tissues.

\begin{tabular}{|c|c|c|c|c|}
\hline \multirow[b]{2}{*}{ Variables } & \multirow[b]{2}{*}{$\mathrm{n}$} & \multicolumn{2}{|c|}{$\begin{array}{c}\operatorname{miR}-338-3 p \\
\text { expression, }(n, \%)\end{array}$} & \multirow[b]{2}{*}{$\mathrm{P}$-value } \\
\hline & & Low & High & \\
\hline Age (years) & & & & $>0.05$ \\
\hline$<55$ & 23 & $13(56.5)$ & $10(43.5)$ & \\
\hline$\geq 55$ & 25 & $15(60)$ & $10(40)$ & \\
\hline Sex & & & & $>0.05$ \\
\hline Male & 21 & $12(57.1)$ & $9(42.9)$ & \\
\hline Female & 27 & $16(59.3)$ & $11(40.7)$ & \\
\hline TNM stage & & & & $<0.01$ \\
\hline $\mathrm{T} 1-\mathrm{T} 2$ & 34 & $15(44.1)$ & $19(55.9)$ & \\
\hline $\mathrm{T} 3-\mathrm{T} 4$ & 14 & $13(92.9)$ & $1(7.1)$ & \\
\hline Tumor size $(\mathrm{cm})$ & & & & $>0.05$ \\
\hline$<5$ & 31 & $17(45.7)$ & $14(54.3)$ & \\
\hline$\geq 5$ & 17 & $11(64.7)$ & $6(35.6)$ & \\
\hline $\begin{array}{l}\text { Lymph node } \\
\text { metastasis }\end{array}$ & & & & $<0.01$ \\
\hline No & 35 & $16(37.1)$ & $19(62.9)$ & \\
\hline Yes & 13 & $12(92.3)$ & $1(7.7)$ & \\
\hline
\end{tabular}

miR, microRNA; RCC, renal cell carcinoma.

assay (Sigma-Aldrich; Merck KGaA, Darmstadt, Germany). Briefly, transfected cells $\left(5 \times 10^{3}\right.$ cells/well) were seeded into 24-well plates, and cultured in DMEM containing $10 \%$ FBS for 24 to $72 \mathrm{~h}$ at $37^{\circ} \mathrm{C}$. At 24,48 and $72 \mathrm{~h}, 100 \mu \mathrm{l}$ of fresh DMEM medium containing $0.5 \mathrm{mg} / \mathrm{ml} \mathrm{MTT}$ and $10 \% \mathrm{FBS}$, was added into the plate, and incubated at $37^{\circ} \mathrm{C}$ for $4 \mathrm{~h}$. Subsequently, $150 \mu$ l dimethyl sulfoxide (Sigma-Aldrich; Merck KGaA) was added to each well for $10 \mathrm{~min}$ at $37^{\circ} \mathrm{C}$. Proliferation of cells was evaluated using a Synergy HT Multi-Mode Microplate reader (BioTek Instruments, Inc., Winooski, VT, USA) at a wavelength of $490 \mathrm{~nm}$.

For the colony formation assay, 786-O and Caki-1 transfected cells were seeded into 6-well plates at a density of 500 cells/well, and cultured in DMEM medium containing $10 \% \mathrm{FBS}$ at $37^{\circ} \mathrm{C}$ for 2 weeks. Cells were subsequently washed twice with phosphate-buffered saline (PBS), and fixed with $4 \%$ paraformaldehyde for $20 \mathrm{~min}$ at room temperature $\left(20-25^{\circ} \mathrm{C}\right.$ ) and stained with $1 \%$ crystal violet (Sigma-Aldrich; Merck KGaA) for $5 \mathrm{~min}$ at room temperature $\left(20-25^{\circ} \mathrm{C}\right)$. Colony formation was imaged and counted in five randomly selected fields under a light microscope (Olympus, Tokyo, Japan).

Migration and invasion assays. For the migration assay of 768-O and Caki-1 cells, a wound healing assay was performed in 6 -well plates at a density of $2 \times 10^{4}$ cells/well. After $24 \mathrm{~h}$ of transfection, a linear wound in the cellular monolayer was created by scraping the confluent cell monolayer with a $200-\mu 1$ sterile pipette tip and washing twice with PBS. The migration of cells was observed at 0 and $24 \mathrm{~h}$ after 
A

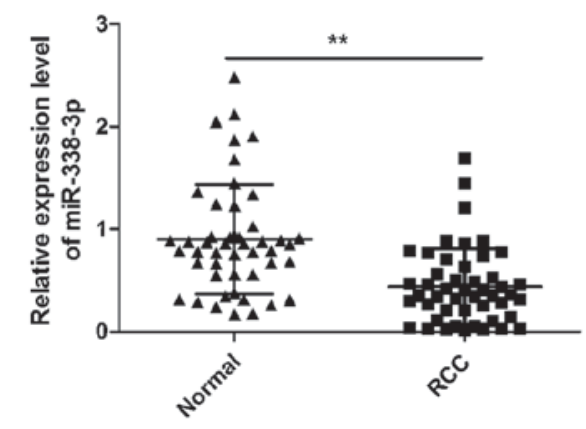

B

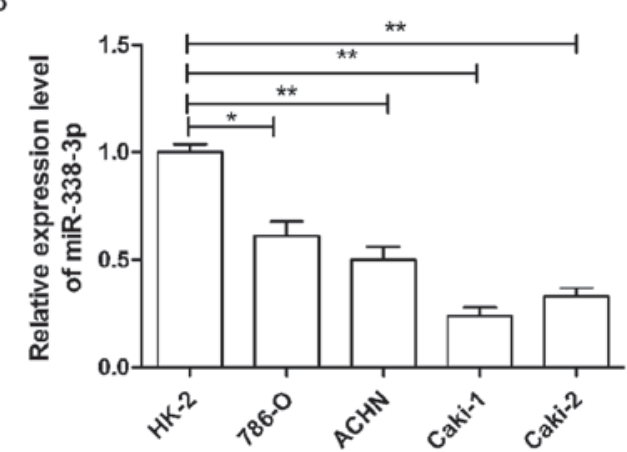

Figure 1. miR-338-3p expression is downregulated in RCC tissues and cell lines. (A) Relative expression of miR-338-3p in 48 pairs of human RCC tissue samples and adjacent normal tissues was detected by RT-qPCR. (B) Relative expression of miR-338-3p expression in four human RCC cell lines (786-O, ACHN, Caki-1 and Caki-2) and a human renal proximal tubule epithelial cell line (HK-2) was detected by RT-qPCR. ${ }^{*} \mathrm{P}<0.05$, ${ }^{* *} \mathrm{P}<0.01$ as indicated. miR, microRNA; $\mathrm{RCC}$, renal cell carcinoma; RT-qPCR, reverse transcription-quantitative polymerase chain reaction.

wounding and then photographed under a light microscope (magnification, x100).

For the invasion assay, $1.0 \times 10^{5} 786-\mathrm{O}$ and Caki-1 transfected cells in serum-free medium were seeded into the upper chamber of Transwell inserts (Corning, Inc., Corning, NY, USA) pre-coated with Matrigel (BD Biosciences, San Jose, CA, USA). The lower chamber was filled with $600 \mu 1$ DMEM supplemented with $10 \%$ FBS as a chemoattractant. Following incubation for $48 \mathrm{~h}$ at $37^{\circ} \mathrm{C}$, non-invading cells on the upper surface of the membrane were removed using cotton swabs, while the invasive cells that attached to the lower surface of the membrane insert were fixed with $4 \%$ paraformaldehyde for $20 \mathrm{~min}$ at room temperature $\left(20-25^{\circ} \mathrm{C}\right)$, stained with $1 \%$ crystal violet solution for $5 \mathrm{~min}$ at room temperature $\left(20-25^{\circ} \mathrm{C}\right)$, then counted in five random fields per well under a light microscope.

Dual-luciferase reporter assay. Prediction of miR-338-3p targets was performed using three publicly available algorithms: TargetScan (www.targetscan.org), miRanda (www.microrna.org) and PicTar (www.pictar.org). SOX4 was selected as a target gene of miR-338-3p. The 3'-UTR of SOX4 that contained the wild-type or mutant putative binding site of miR-338-3p was inserted into the psiCHECK2 vector (Promega). For the dual-luciferase reporter assay, 2.0 $\times 10^{4}$ 786-O and Caki-1 cells/well were seeded into 24-well plates and co-transfected with $200 \mathrm{ng}$ of wild-type or mutant SOX4 reporter plasmid and $100 \mathrm{nM}$ of miR-338-3p mimic or miR-NC, and the pRL-TK plasmid (Promega), which was used for internal normalization, using Lipofectamine 2000 (Invitrogen; Thermo Fisher Scientific, Inc.), according to the manufacturer's instructions. After $48 \mathrm{~h}$ of transfection, a luciferase reporter gene assay was implemented using the Dual-Luciferase Reporter Assay system (Promega), according to the manufacturer's instructions. Renilla luciferase acitivity was used for normalization.

Western blot analysis. Protein from the 786-O and Caki-1 transfected cells was extracted on ice in radioimmunoprecipitation assay lysis buffer supplemented with protease inhibitor (both from Beyotime Institute of Biotechnology, Shanghai, China), and protein concentrations were determined using the Bradford assay (Bio-Rad Laboratories, Inc., Hercules, CA, USA). Proteins (20 $\mu \mathrm{g}$ of each sample) were separated by $10 \%$ SDS-PAGE and transferred to nitrocellulose membranes (EMD Millipore, Billerica, MA, USA) at $80 \mathrm{~V}$ for $2 \mathrm{~h}$ at $4^{\circ} \mathrm{C}$. Following blocking in 5\% non-fat milk in PBS for $2 \mathrm{~h}$ at $37^{\circ} \mathrm{C}$, the membranes were probed with primary antibodies overnight at $4^{\circ} \mathrm{C}$ as follows: Mouse monoclonal anti-human SOX4 (1:1,000, cat. no. sc-365964; Santa Cruz Biotechnology, Inc., Dallas, TX, USA) and mouse monoclonal anti-human GAPDH (1:5,000, cat. no. sc-365062; Santa Cruz Biotechnology, Inc.). Subsequently, the membranes were incubated with polyclonal goat anti-mouse horseradish peroxidase-conjugated immunogloblin $\mathrm{G}(1: 10,000$, cat. no. sc-2005; Santa Cruz Biotechnology, Inc.) for $2 \mathrm{~h}$ at room temperature. Protein bands were visualized on X-ray film using a chemiluminescent detection system (Beyotime Institute of Biotechnology).

Statistical analysis. Quantitative data were presented as the mean \pm standard deviation from at least three independent experiments with similar results. Student's t-tests or one-way analysis of variance with Tukey's post hoc tests were used to assess the differences between different groups using SPSS v19.0 (IBM Corp., Armonk, NY, USA). The correlations between miR-338-3p expression and SOX4 mRNA in patients with RCC were analyzed using Spearman's rank test. $\mathrm{P}<0.05$ was considered to indicate a statistically significant difference.

\section{Results}

miR-338-3p expression is downregulated in RCC tissues and cell lines. To investigate miR-338-3p expression in RCC, RT-qPCR was performed in 48 pairs of human RCC and their adjacent normal tissue samples. As demonstrated in Fig. 1A, the expression of miR-338-3p was significantly lower in RCC tissues than in the corresponding adjacent normal tissues $(\mathrm{P}<0.01)$. In addition, the association between miR-338-3p expression and the clinicopathological parameters of the patients were analyzed. It was observed that miR-338-3p expression was significantly associated with TNM stage and lymph node metastasis (both $\mathrm{P}<0.01$ ), but not with age, sex or tumor size (Table I). Next, miR-338-3p expression in four 
A

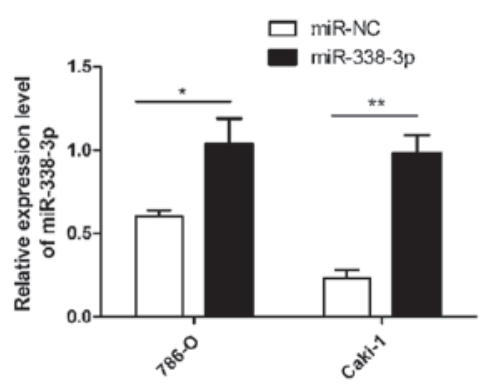

C

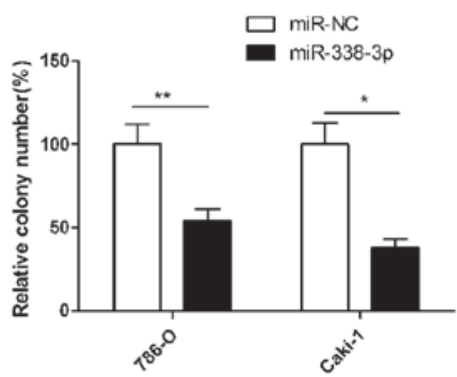

B
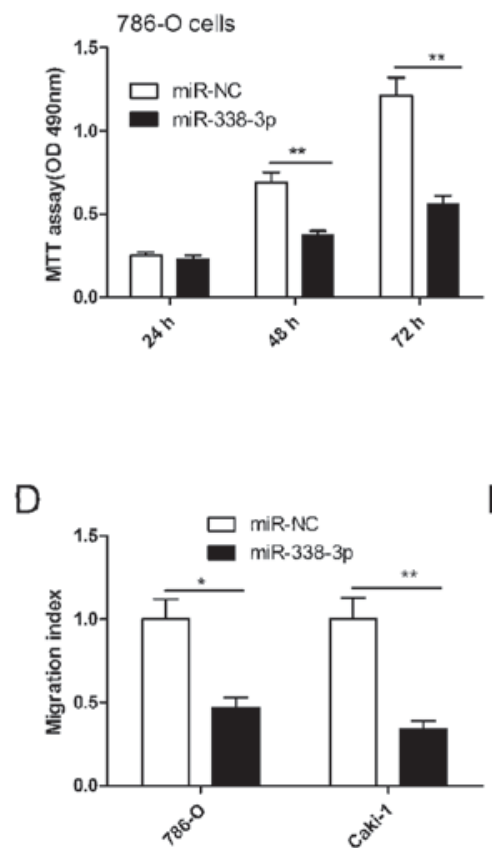
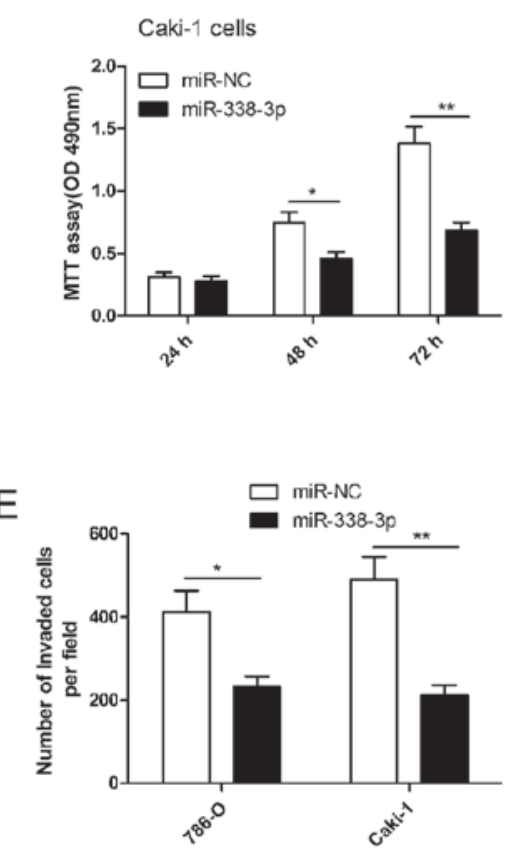

Figure 2. miR-338-3p inhibits cell proliferation, colony formation, migration and invasion of RCC cells. (A) Reverse transcription-quantitative polymerase chain reaction analysis of miR-338-3p expression (relative to U6 expression) in RCC cells following transfection with miR-338-3p mimic or miR-NC. (B) Cell proliferation, (C) colony formation, (D) migration and (E) invasion were determined in RCC cells following transfection with miR-338-3p or miR-NC. ${ }^{*}<0.05$, ${ }^{* * *} \mathrm{P}<0.01$ as indicated. miR, microRNA; RCC, renal cell carcinoma; NC, negative control; OD, optical density.

human RCC cell lines was analyzed. It was demonstrated that the expression of miR-338-3p in the RCC cell lines, 786-O, ACHN, Caki-1 and Caki-2, was significantly lower than that observed in the human renal proximal tubule epithelial cell line, HK-2 ( $\mathrm{P}<0.05$; Fig. 1B). Cell line 786-O, which had the highest expression of miR-338-3p of the four RCC cell lines, and Caki-1, which had the lowest expression of miR-338-3p of the four cell lines, were selected as representatives to perform subsequent experiments.

miR-338-3p inhibits RCC cell proliferation, colony formation, migration and invasion. To investigate the potential role of miR-338-3p in regulating RCC cell growth and metastasis, miR-338-3p was overexpressed in 786-O and Caki-1 cells by transfection with an miR-338-3p mimic. RT-qPCR demonstrated that the miR-338-3p mimic significantly upregulated the level of miR-338-3p expression in the two cell lines compared with cells transfected with miR-NC $(\mathrm{P}<0.05$; Fig. 2A). Subsequently, cell proliferation, colony formation, migration and invasion were determined in RCC cells transfected with miR-338-3p. It was demonstrated that miR-338-3p significantly inhibited RCC cell proliferation $(\mathrm{P}<0.01)$, colony formation $(\mathrm{P}<0.05)$, migration $(\mathrm{P}<0.05)$ and invasion $(\mathrm{P}<0.05)$ in both cells lines compared with cells transfected with miR-NC (Fig. 2B-E). These results implied that miR-338-3p has a suppressive role in RCC cells.

SOX4 is a direct downstream target of $m i R-338-3 p$ in $R C C$ cells. To investigate the molecular mechanisms by which miR-338-3p inhibits RCC progression, bioinformatics database (TargetScan, PicTar and miRanda) analyses were used to predict putative miR-338-3p targets. SOX4 was selected as a direct target of miR-338-3p based on putative target sequences at 1289-1295 bp of SOX4 (Fig. 3A). To further confirm targeting of SOX4 by miR-338-3p, a luciferase activity assay was performed. As demonstrated in Fig. 3B, miR-338-3p overexpression significantly inhibited wild-type SOX4 3'-UTR reporter activity compared with the cells transfected with miR-NC $(\mathrm{P}<0.01)$, while had no inhibition effect on the mutant SOX4 3'-UTR reporter activity. In addition, it was observed that overexpression of miR-338-3p induced significant downregulation of SOX4 expression at the mRNA level $(\mathrm{P}<0.01)$ and marked downregulation of SOX4 at the protein level compared with cells transfected with miR-NC (Fig. 3C and D) in both 786-O and Caki-1 cells. These results implied that miR-338-3p suppressed SOX4 expression by binding to the 3'-UTR of SOX4 mRNA.

SOX4 is upregulated and inversely correlated with $\mathrm{miR}-338-3 p$ in RCC tissues. To further explore the relationship between miR-338-3p and SOX4 in RCC, the expression of SOX4 at the mRNA level in RCC tissues and adjacent normal tissues was examined by RT-qPCR. It was demonstrated that the expression of SOX4 was significantly increased in RCC tissues compared with adjacent normal tissues $(\mathrm{P}<0.01$; Fig. $4 \mathrm{~A})$. A statistically significant inverse correlation was observed between expression levels of miR-338-3p and SOX4 mRNA in RCC tissues through Spearman's correlation analysis ( $r=-0649, \mathrm{P}<0.0001$; Fig. 4B).

Overexpression of SOX4 reverses the inhibition effect induced by miR-338-3p mimics in RCC cells. To evaluate whether SOX4 is responsible for the functional effects of miR-338-3p in RCC cells, RCC cells were co-transduced with miR-338-3p mimics or miR-NC and SOX4 overexpression plasmid. 

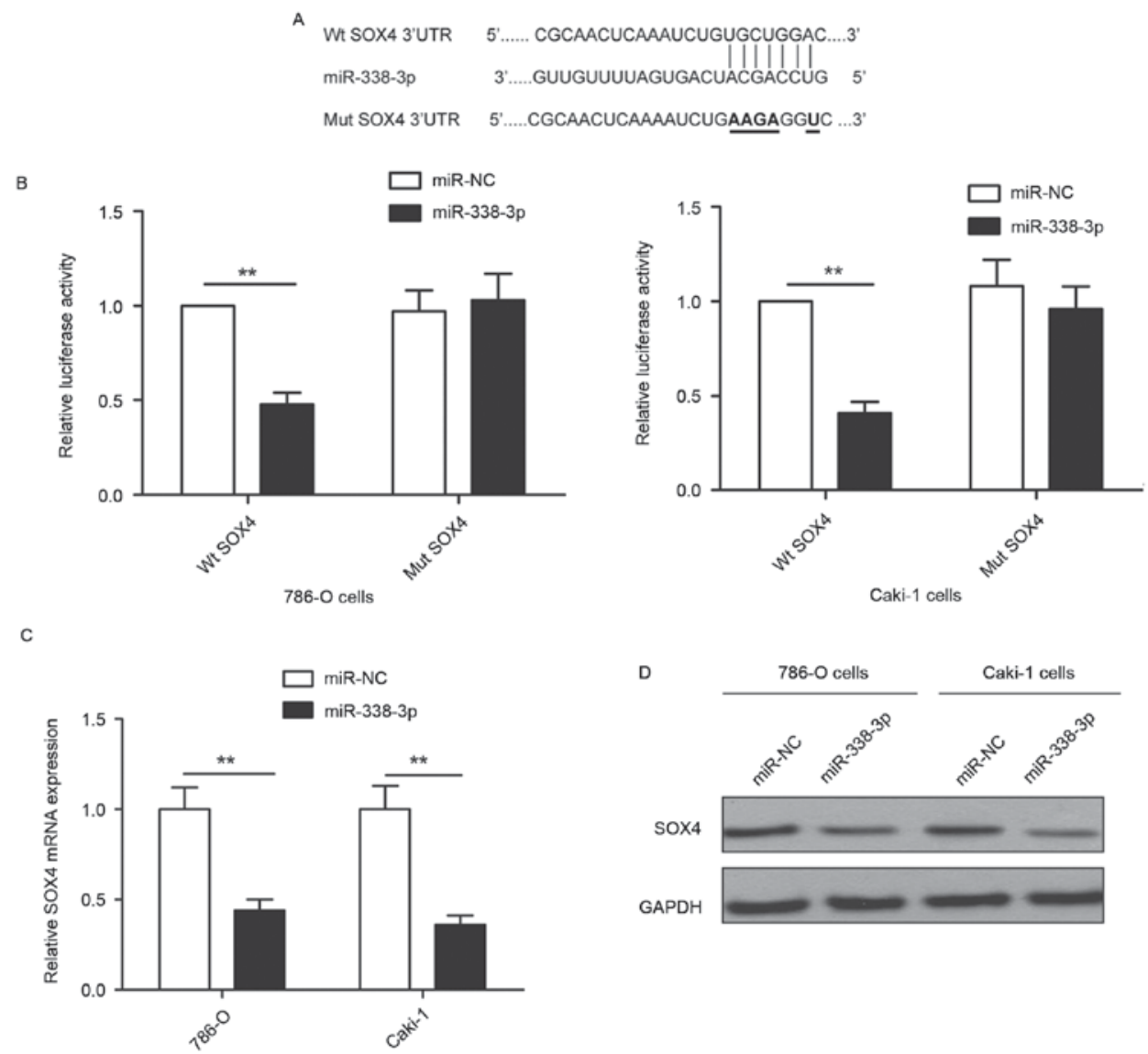

Figure 3. SOX4 is a direct target of miR-338-3p in RCC. (A) The luciferase reporter of the miR-338-3p binding site on the Wt and Mut SOX4 3'-UTR. The replaced site is underlined. (B) The luciferase activity was measured following co-transfection with luciferase reporter plasmids (Wt or Mut SOX4 3'-UTR), with miR-338-3p mimics or NC in RCC cells. (C) Reverse transcription-quantitative polymerase chain reaction analysis of SOX4 mRNA expression in RCC cells following transfection with miR-338-3p or miR-NC. (D) Western blot analysis of SOX4 protein expression in RCC cells following transfection with miR-338-3p or miR-NC. ${ }^{* *} \mathrm{P}<0.01$ as indicated. SOX4, sex-determining region Y-box 4; miR, microRNA; RCC, renal cell carcinoma; Wt, wild-type; Mut, mutant; UTR, untranslated region; NC, negative control.
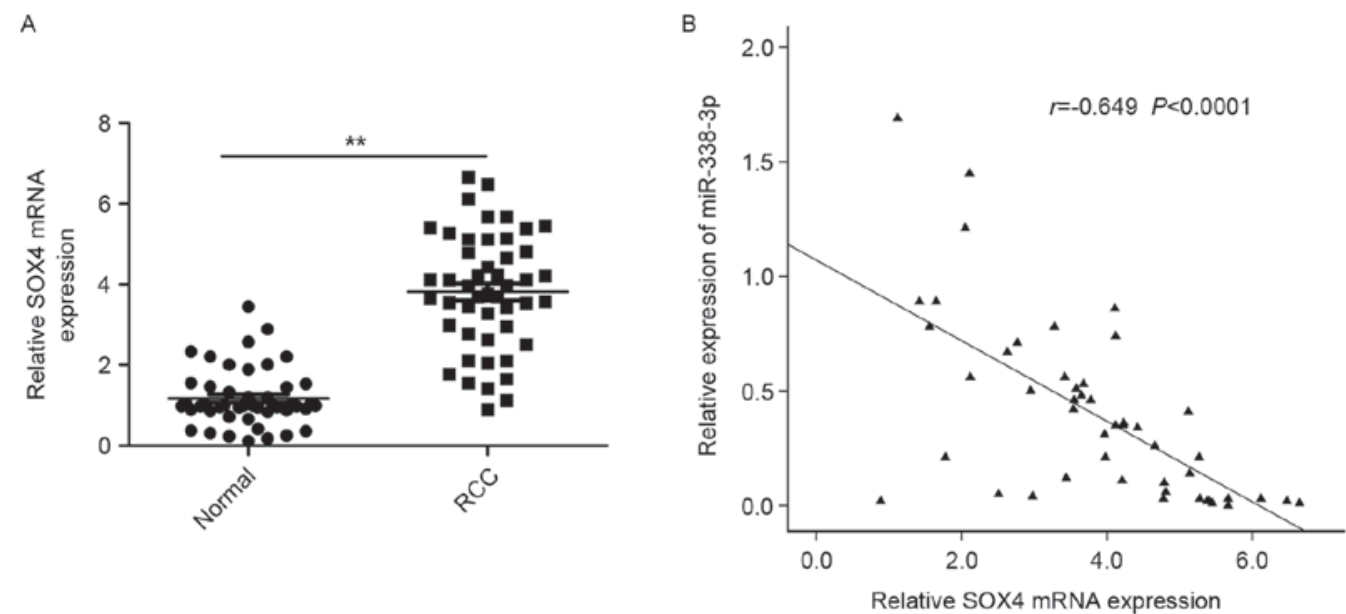

Figure 4. SOX4 is upregulated and inversely correlated with miR-338-3p in RCC tissues. (A) SOX4 mRNA expression level was determined in 48 pairs of RCC tissues and adjacent normal tissues by reverse transcription-quantitative polymerase chain reaction. (B) Spearman's correlation analysis was used to determine the correlation between the expression levels of SOX4 and miR-338-3p in RCC tissues $(n=48) .{ }^{* *} \mathrm{P}<0.01$ as indicated. SOX4, sex-determining region Y-box 4; miR, microRNA; RCC, renal cell carcinoma.

Following this, cell proliferation, colony formation, migration and invasion assays were performed. Western blotting demonstrated that RCC cells transfected with miR-338-3p mimic had markedly decreased SOX4 expression, while cells co-transfected with miR-338-3p mimics plus SOX4 plasmid restored SOX4 protein expression (Fig. 5A). In addition, it was also observed that SOX4 overexpression significantly reversed the effect on cell proliferation, colony formation, migration and 
A

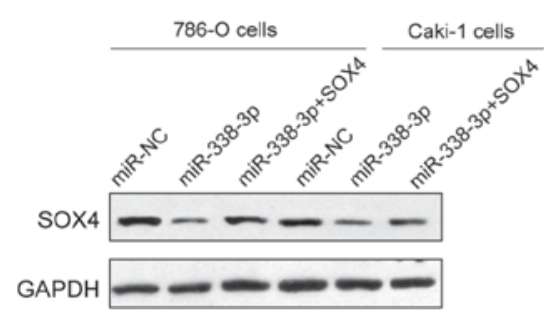

C

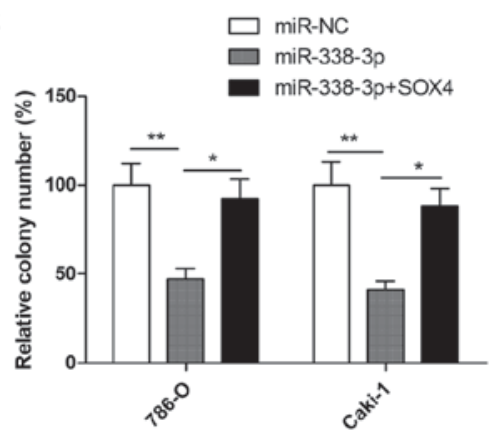

B

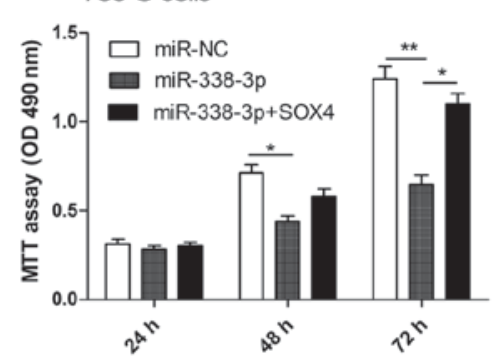

D

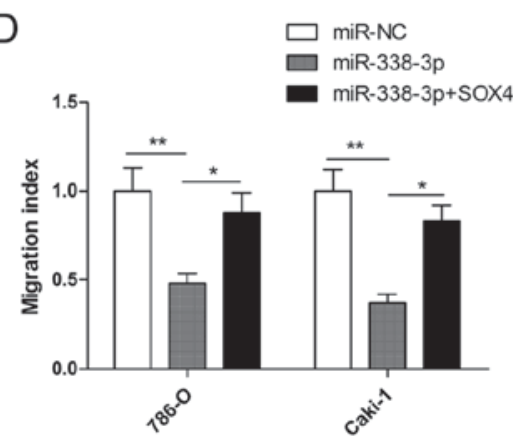

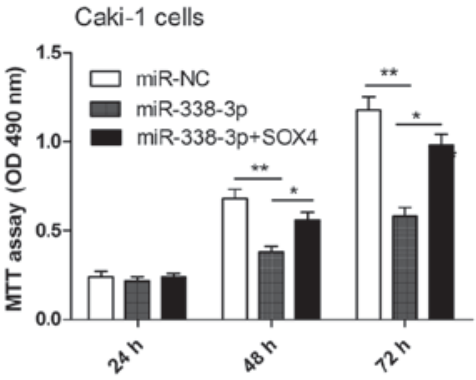
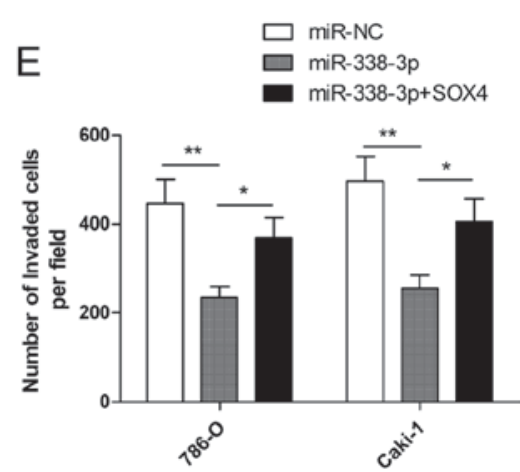

Figure 5. Overexpression of SOX4 reverses the inhibition effect induced by miR-338-3p mimic in RCC cells. (A) SOX4 protein expression was determined in RCC cells co-transfected with miR-338-3p mimic or miR-NC and SOX4 overexpression vector. (B) Cell proliferation, (C) colony formation, (D) migration and (E) invasion were determined in RCC cells co-transfected with miR-338-3p mimic or miR-NC and $\mathrm{SOX} 4$ overexpression vector. ${ }^{*} \mathrm{P}<0.05$ and ${ }^{* *} \mathrm{P}<0.01$ as indicated. SOX4, sex-determining region Y-box 4; miR, microRNA; RCC, renal cell carcinoma; NC, negative control; OD, optical density.

invasion (all $\mathrm{P}<0.05)$ in RCC cells induced by the miR-338-3p mimic (Fig. 5B-E).

\section{Discussion}

miR, as important regulators, have been documented to have crucial roles in renal cancer development by regulating cell proliferation, apoptosis and metastasis $(9,10)$. Data from the present study provided evidence that miR-338-3p is deficient in RCC tissues and cell lines, and is associated with TNM stage and lymph node metastasis. The in vitro experiments demonstrated that restoration of miR-338-3p repressed cell proliferation, colony formation, migration and invasion of RCC cells. Regarding the underlying mechanisms, the present results indicated that the direct targeting of SOX4 may contribute to the functions of $\mathrm{miR}-338-3 \mathrm{p}$ in the above processes. Although substantial study is required to further explore the underlying mechanisms of miR-338-3p in growth and metastasis, the present study has provided vital clues to characterize the key roles of miR-338-3p in RCC and facilitate its application for future treatment strategies for RCC.

miR-338-3p, located at chromosome 17q25.3, has been reported to function as a tumor suppressor in many types of cancer, such as hepatocellular carcinoma $(11,12)$, colorectal cancer (13), ovarian cancer $(14)$, gastric cancer $(15,16)$ and breast cancer (17). It has important roles in cell proliferation, migration and invasion by targeting multiple genes, such as smoothened, cyclin D1, phosphatidylinositol-3,4,5-trisphosphate-dependent Rac exchange factor 2a, SSX family member 2 interacting protein and zinc finger E-box binding homeobox 2 (11-17,20,21). However, the biological function of miR-338-3p and its related molecular pathways involved in the progression of RCC have not been fully elucidated. The present study demonstrated that the expression miR-338-3p was significantly lower in RCC tissues and cell lines than in the adjacent normal tissues and normal renal cells. Cellular function of miR-338-3p in RCC demonstrated that miR-338-3p overexpression inhibited cell proliferation, colony formation, migration and invasion of RCC cells. These results suggested that miR-338-3p may serve as tumor suppressor in RCC.

SOX 4, a member of the SOX family of transcription factors, has been demonstrated to be overexpressed in several types of human cancer, including esophageal squamous cell carcinoma (22), prostate cancer (23), colon cancer (24), breast cancer (25), hepatocellular carcinoma (26) and non-small cell lung cancer (27). SOX4 also contributes to cell survival and metastasis in many cancer types by regulating epithelial-to-mesenchymal transition $(23,28-30)$. It is also well recognized that miR-338-3p overexpression leads to downregulation of SOX4 in non-small cell lung cancer (31) and breast cancer (17); however, prior to the present study, this had not been demonstrated in RCC. As expected, the present results indicated that miR-338-3p was able to bind directly to the 3'-UTR of SOX4 mRNA and suppress SOX4 mRNA and protein expression in RCC cells. It was also demonstrated that SOX4 expression was upregulated, and inversely correlated with miR-338-3p expression in RCC tissue specimens. Furthermore, SOX4 was responsible for miR-338-3p-induced modulation of proliferation, colony formation, migration and 
invasion of RCC cells. These results indicated that miR-338-3p may exert biological functions in growth and metastasis of RCC cells by targeting SOX4.

In summary, the present study provided more evidence that miR-338-3p expression was downregulated in RCC tissues and cell lines, was associated with TNM stage and lymph node metastasis, and that miR-338-3p was able to inhibit cell proliferation, colony formation, migration and invasion of RCC cells by repressing SOX4. These findings suggested that miR-338-3p may provide a novel therapeutic strategy for the treatment of patients with advanced RCC.

\section{References}

1. Siegel R, Ma J, Zou Z and Jemal A: Cancer statistics, 2014. CA Cancer J Clin 64: 9-29, 2014

2. Pantuck AJ, Zisman A and Belldegrun AS: The changing natural history of renal cell carcinoma. J Urol 166: 1611-1623, 2001.

3. Chow WH, Dong LM and Devesa SS: Epidemiology and risk factors for kidney cancer. Nat Rev Urol 7: 245-257, 2010.

4. Guo H, Ingolia NT, Weissman JS and Bartel DP: Mammalian microRNAs predominantly act to decrease target mRNA levels. Nature 466: 835-840, 2010.

5. Bartel DP: MicroRNAs: Genomics, biogenesis, mechanism, and function. Cell 116: 281-297, 2004.

6. Fabian MR, Sonenberg N and Filipowicz W: Regulation of mRNA translation and stability by microRNAs. Annu Rev Biochem 79: 351-379, 2010.

7. Farazi TA, Spitzer JI, Morozov P and Tuschl T: miRNAs in human cancer. J Pathol 223: 102-115, 2011.

8. Garzon R and Marcucci G: Potential of microRNAs for cancer diagnostics, prognostication and therapy. Curr Opin Oncol 24: 655-659, 2012.

9. Kurozumi A, Goto Y, Okato A, Ichikawa T and Seki N Aberrantly expressed microRNAs in bladder cancer and renal cell carcinoma. J Hum Genet 62: 49-56, 2017.

10. Gu L, Li H, Chen L, Ma X, Gao Y, Li X, Zhang Y, Fan Y and Zhang X: MicroRNAs as prognostic molecular signatures in renal cell carcinoma: A systematic review and meta-analysis. Oncotarget 6: 32545-32560, 2015

11. Huang XH, Chen JS, Wang Q, Chen XL, Wen L, Chen LZ, Bi J, Zhang LJ, Su Q and Zeng WT: miR-338-3p suppresses invasion of liver cancer cell by targeting smoothened. J Pathol 225 463-472, 2011

12. Fu X, Tan D, Hou Z, Hu Z, Liu G, Ouyang Y and Liu F: The effect of miR-338-3p on HBx deletion-mutant (HBx-d382) mediated liver-cell proliferation through CyclinD1 regulation. PloS One 7: e43204, 2012.

13. Sun K, Deng HJ, Lei ST, Dong JQ and Li GX: miRNA-338-3p suppresses cell growth of human colorectal carcinoma by targeting smoothened. World J Gastroenterol 19: 2197-2207, 2013.

14. Wen C, Liu X, Ma H, Zhang W and Li H: miR3383p suppresses tumor growth of ovarian epithelial carcinoma by targeting Runx2. Int J Oncol 46: 2277-2285, 2015.

15. Li P, Chen X, Su L, Li C, Zhi Q, Yu B, Sheng H, Wang J, Feng R, Cai $\mathrm{Q}$, et al: Epigenetic silencing of miR-338-3p contributes to tumorigenicity in gastric cancer by targeting SSX2IP. PloS One 8: e66782,2013.
16. Guo B, Liu L, Yao J, Ma R, Chang D, Li Z, Song T and Huang C: miR-338-3p suppresses gastric cancer progression through a PTEN-AKT axis by targeting P-REX2a. Mol Cancer Res 12: 313-321, 2014.

17. Jin Y, Zhao M, Xie Q, Zhang H, Wang Q and Ma Q: MicroRNA-338-3p functions as tumor suppressor in breast cancer by targeting SOX4. Int J Oncol 47: 1594-1602, 2015.

18. Chen X, Ruan A, Wang X, Han W, Wang R, Lou N, Ruan H, Qiu B, Yang $\mathrm{H}$ and Zhang $\mathrm{X}$ : miR-129-3p, as a diagnostic and prognostic biomarker for renal cell carcinoma, attenuates cell migration and invasion via downregulating multiple metastasis-related genes. J Cancer Res Clin Oncol 140: 1295-1304, 2014.

19. Livak KJ and Schmittgen TD: Analysis of relative gene expression data using real-time quantitative PCR and the 2(-Delta Delta C(T)) method. Methods 25: 402-408, 2001.

20. Wang G, Sun Y, He Y, Ji C, Hu B and Sun Y: MicroRNA-338-3p inhibits cell proliferation in hepatocellular carcinoma by target forkhead box P4 (FOXP4). Int J Clin Exp Pathol 8: 337-344, 2015.

21. Huang N, Wu Z, Lin L, Zhou M, Wang L, Ma H, Xia J, Bin J, Liao Y and Liao W: miR-338-3p inhibits epithelial-mesenchymal transition in gastric cancer cells by targeting ZEB2 and MACC1/Met/Akt signaling. Oncotarget 6: 15222-15234, 2015.

22. Han R, Huang S, Bao Y, Liu X, Peng X, Chen Z, Wang Q, Wang J, Zhang Q, Wang T, et al: Upregulation of SOX4 antagonizes cellular senescence in esophageal squamous cell carcinoma. Oncol Lett 12: 1367-1372, 2016.

23. Wang L, Zhang J, Yang X, Chang YW, Qi M, Zhou Z, Zhang J and Han B: SOX4 is associated with poor prognosis in prostate cancer and promotes epithelial-mesenchymal transition in vitro. Prostate Cancer Prostatic Dis 16: 301-307, 2013.

24. Lin CM, Fang CL, Hseu YC, Chen CL, Wang JW, Hsu SL, Tu MD, Hung ST, Tai C, Uen YH and Lin KY: Clinical and prognostic implications of transcription factor SOX4 in patients with colon cancer. PloS One 8: e67128, 2013.

25. Song GD, Sun Y, Shen H and Li W: SOX4 overexpression is a novel biomarker of malignant status and poor prognosis in breast cancer patients. Tumour Biol 36: 4167-4173, 2015.

26. Hur W, Rhim H, Jung CK, Kim JD, Bae SH, Jang JW, Yang JM, Oh ST, Kim DG, Wang HJ, et al: SOX4 overexpression regulates the p53-mediated apoptosis in hepatocellular carcinoma: Clinical implication and functional analysis in vitro. Carcinogenesis 31: 1298-1307, 2010.

27. Wang D, Hao T, Pan Y, Qian X and Zhou D: Increased expression of SOX4 is a biomarker for malignant status and poor prognosis in patients with non-small cell lung cancer. Mol Cell Biochem 402: 75-82, 2015.

28. Yu CC, Chen PN, Peng CY, Yu CH and Chou MY: Suppression of miR-204 enables oral squamous cell carcinomas to promote cancer stemness, EMT traits and lymph node metastasis. Oncotarget 7: 20180-20192, 2016.

29. Shi S, Cao X, Gu M, You B, Shan Y and You Y: Upregulated expression of SOX4 is associated with tumor growth and metastasis in nasopharyngeal carcinoma. Dis Markers 2015: 658141, 2015.

30. Parvani JG and Schiemann WP: Sox4, EMT programs, and the metastatic progression of breast cancers: Mastering the masters of EMT. Breast Cancer Res 15: R72, 2013.

31. Li Y, Chen P,Zu L, Liu B, Wang M and Zhou Q: MicroRNA-338-3p suppresses metastasis of lung cancer cells by targeting the EMT regulator Sox4. Am J Cancer Res 6: 127-140, 2016. 